\title{
China Historical Christian Database: Mapeamento do Passado Cristão da China
}

\author{
Robert Martins Junqueira ${ }^{1}$ \\ ${ }^{1}$ Affiliation not available
}

June 7, 2021

Este texto foi redigido para a disciplina de Conceitos e Práticas de Gestão de Inovação da Pós-Graduação em Gestão e Políticas de Ciência e Tecnologia da Faculdade de Ciências Sociais e Humanas da Universidade NOVA de Lisboa, ministrada por Filipa Borrego e Sandra Aresta.

O projeto «China Historical Christian Database» (doravante CHCD) constitui, apesar de ainda in fieri, uma ferramenta inovadora e avançada destinada à valorização do conhecimento sobre a presença dos cristianismos na China entre 1550 e 1950. A CHCD promete tornar-se essencial para qualquer investigador/a dedicada/o à temática da história dos cristianismos na China e às temáticas relacionadas - como seja a de uma cristandade própria da China - conquanto o/a utilizador/a seja capaz de ler em língua inglesa ou nos padrões de escritaseja tradicional ou simplificado - da língua chinesa. Por intermédio do desenvolvimento de uma pioneira base de dados digital geográfica e de relações - nomeadamente entre indivíduos, instituições e eventos-mais uma arrojada plataforma educativa em linha - ainda em fase beta mas já disponível em acesso aberto-, e ainda por via do estabelecimento de parcerias estratégicas de índole internacional, a CHCD proporciona uma solução tecnológica inteiramente nova para fazer face a certos problemas típicos da investigação histórica sobre os cristianismos na China e da transmissão dos conhecimentos concernentes, como sejam a pluralidade linguística e a dispersão geográfica das fontes. A abordagem definida no seio do projecto, de orientação marcadamente computacional, é de abertura para o desenvolvimento contínuo, pois o que se procura é que a CHCD evolua de forma constante no tempo e que permita o desencadeamento de transformações no íntimo da própria área de investigação em que a mesma se insere, abrindo o caminho para formas inéditas de transmissão e análise na hora valorizar e aprofundar o conhecimento sobre a história os cristianismos na China ao longo de 400 anos. Assim - se bem que não aprofundaremos o que se segue no presente trabalho—, a CHCD promete provocar um efeito disruptivo no que aos modelos de investigação na sua área, tão inatuais e por vezes caducos, diz respeito. Esta inovadora base de dados, alojada pelo Center for Global Christianity and Mission da Boston University - mas que envolve o Center for the Study of Asia, o Institute on Culture, Religion \& World Affairs, o Rafik B. Hariri Institute for Computing and Computational Science \& Engineering (estes três da Boston University), o Instituto de História Qing da Universidade Renmin da China, o Ricci Institute for Chinese-Western Cultural History da University of San Francisco, a SOAS University of London, os Passionist Historical Archives, o Monumenta Serica Institute, o Institute for Advanced Jesuit Studies do Boston College, a Whitworth University, a Università degli Studi di Perugia, o Centro Científico e Cultural de Macau, I.P. (e portanto também a Fundação Jorge Álvares), a Università degli Studi di Napoli "L'Orientale" e os Carleton College Archives - pode ser acedida in https://chcdatabase.com/. Ao longo das páginas que se seguem, iremos argumentar que a CHCD representa uma inovação de tipo aberto, social e tecnológico. Por forma a argumentar que a CHCD representa uma inovação no seu contexto disciplinar -inovação, aliás, potencialmente muito lucrativa em termos de conhecimento-, iremos basear-nos numa leitura aberta - e, bem sabemos, com potencial de gerar controvérsia - da noção de inovação como sendo orientada também para o ramo particular da economia que aqui nos interessa: a economia da investigação. 


\section{1: Inovação orientada para a economia da investigação}

Falar de ëconomia da investigação (economy of research)" é apontar para aquilo que Charles S. Peirce considerou ser, "de todos os ramos da economia, talvez o mais rentável (of all the branches of economy, [...] perhaps the most profitable)" (Peirce 1931-1958 [1902], vol. 7 pará. 161). Talvez as palavras de Peirce soem um tanto ou quanto exageradas para quem não tiver em conta que na economia da investigação não se trata de lucrar a nível de verbas, mas de verbos - quero dizer, conhecimento -, sem por isso desconsiderar o papel daquelas no investimento que se faz em ciência, nem mesmo a possibilidade de que o financiamento atribuído à investigação acabe por estar na origem de uma série de desenvolvimentos que venham a desembocar em avultados ganhos a nível monetário ou de outra ordem, no seio de outros ramos da economia. É verdade que a economia da investigação não existe à margem, isolada no fim do mundo, sem relacionar-se com a economia como um todo. Tem, ainda assim, a sua esfera própria-uma esfera aberta e em relação, mas própria-, e a análise que se atenha ao nível da economia da investigação deve ter em conta que aquilo que se procura nesse ramo da economia não é aumentar a conta bancária ou outra coisa qualquer que não seja $o$ nosso conhecimento. É em conhecimento que a/os tia/os Patinhas da investigação devem banhar-se, e é na distribuição das águas desses banhos que estão os verdadeiros ganhos no âmbito da economia da investigação. Uma investigação que pouco nos traga a nível de conhecimento será sempre, sob a ótica que impera neste texto, um investimento que deu prejuízo. Obviamente, a rentabilidade não se aufere de modo assim tão rude: no terreno da economia é preciso ter em conta a relação entre o investimento e os resultados. Não estamos a dizer nada de novo; leia-se Peirce para um maior detalhe:

Ä doutrina da economia, em geral, trata das relações entre utilidade e custo. O seu ramo relativo à investigação considera as relações entre a utilidade e o custo de diminuir a probabilidade de erro do nosso conhecimento. Tem como principal problema a maneira como, mediante um determinado dispêndio de dinheiro, tempo e energia, se pode obter o mais valioso incremento do nosso conhecimento. (The doctrine of economy, in general, treats of the relations between utility and cost. That branch of it which relates to research considers the relations between the utility and the cost of diminishing the probable error of our knowledge. Its main problem is, how, with a given expenditure of money, time, and energy, to obtain the most valuable addition to our knowledge)" (Ibid. [1876], 7.140).

Sendo o nosso fito argumentar que a CHCD representa uma inovação no seu contexto disciplinar e no âmbito deste ramo específico da economia, o que trataremos nas seguintes secções, iremos sustentar a nossa reflexão numa interpretação aberta (e quiçá inovadora) da noção de inovação, como sendo orientada não só para a economia de mercado mas também para a economia da investigação. Como disse Juma (2016, 258), na esteira de Joseph Schumpeter, a inovação resulta "dos esforços de empresários [ou empreendedora/es] (of the efforts of entrepreneurs)". Ora, no caso da economia da investigação, deve dizer-se que a inovação resulta, antes de tudo, dos esforços de investigadora/es. Também remetendo para Schumpeter, ao expor as questões filosóficas levantadas no corpo de uma call for papers de um evento científico depois recebido pelo St. Annes' College de Oxford em 2016, Vincent Blok $(2018,2)$ apresentou a inovação como sendo ö produto da destruição criativa (the product of creative destruction)", pois toda a inovação "é acompanhada pela destruição das velhas regras e da velha ordem (is accompanied by the destruction of the old rules and the old order)"; e isto que significa que, se a inovação produz um "impacto positivo (positive impact)" nesta ou naquela esfera, tal impacto será ßempre acompanhado por repercussões negativas alhures (always accompanied by negative impacts elsewhere)". Assim, tendo em conta-para além do âmbito da economia que foi derivado do pensamento de Peirce - a transposição que fizemos a partir do texto de Juma e a noção apresentada por Blok (tudo acima), temos um chão firme para dizer que a inovação orientada para a economia da investigação não só resulta dos esforços de quem investiga como também passa pela destruição de velhas regras e de uma velha ordem, tantas vezes obsoletas, produzindo sempre repercussões simultaneamente positivas e negativas, mediante a perspectiva a partir da qual se considere o impacto da inovação. O que nos parece ser sobremaneira difícil na hora de pensar a inovação no âmbito da economia da investigação é i) ultrapassar os velhos hábitos e fazer a transferência desta noção afeta ao mercado para a o ecossistema científico e ii) estimular a comunidade científica para que arrume a casa - o ecossistema científico, sendo que eco remete para 'casa' e sistema para 'arrumação' — de modo a torná-la num ambiente mais amigável para a 
inovação. Quanto à inovação representada pela $\mathrm{CHCD}$, até pode não parecer ter vindo para destruir nada; e, se fossemos a negligenciar a importância da destruição para a inovação, poderíamos dar aqui um belo exemplo do ënviesamento-da-introdução-de-algo-novo (the 'introduction-of-something-new' bias)", alegando que tal enviesamento é na verdade o fruto maduro da evolução no reino das ideias, argumentando que, se assim não fosse, não seria verdade que os ëstudos clássicos (classical studies)" sobre inovação ëxploram a noção Schumpeteriana de destruição criativa (explore the Schumpeterian notion of creative destruction)ë os estudos mais " contemporâneos (contemporary)" se debruçam sobre a noção de "transição tecnológica, inovação social ou inovação reativa", apenas havendo um espaço para consenso perante ä ideia de que a inovação consiste na introdução de algo novo (the idea that innovation is the introduction of something new)" (Goulet e Vinck 2017, 97-98). Contudo, tal não é o caso, pois apesar de toda a novidade trazida pela CHCD, como veremos em seguida, há uma dimensão destrutiva que lhe garante o título de inovação no sentido pleno da palavra, pois um dos fundamentais motivos por detrás da criação da CHCD passa mesmo pela necessidade de arrasar algumas das dificuldades com que se têm deparado, até agora, aquela/es que investigam sobre a história dos cristianismos na China.

\section{2: Inovação aberta, social e tecnológica}

Como veremos em seguida, a CHCD representa um excelente e multifário exemplo de inovação, quer no âmbito disciplinar em que se insere, quer no âmbito mais alargado da economia da investigação. Sem pretendermos esgotar todos os tipos de inovação passíveis de serem reconhecidos nesta conveniente e proveitosa plataforma em linha, iremos assinalar o carácter aberto, social e tecnológico da CHCD.

\section{1: Inovação aberta}

De acordo com Ron Basu (2015, 141-142), o conceito de inovação aberta, por muito simples que pareça ser, tem muito que se lhe diga, pois é preciso pensar muito bem sobre ö que abrir, como abrir e como gerir os problemas novos advindos de tal abertura (what to open, how to open it and how to manage the new problems created by that openness)". No âmbito da CHCD, abriu-se tudo-pois está tudo disponível em acesso aberto-, inclusivamente abrindo os ficheiros que contêm os dados para que a/os utilizadora/es os possam importar para plataformas alheias à CHCD ou mesmo à Neo4j (https://neo4j.com/), que é a plataforma gráfica de bases de dados, de código aberto, na qual a CHCD roda. Mas esta inovação poderia estar apenas formalmente aberta, sendo quiçá de muito difícil compreensão e utilização, o que implicaria que a inovação estaria, no fundo, fechada ao grande público. Tal não é o caso: trata-se mesmo de inovação aberta no sentido luzidio da palavra. A plataforma é fácil de entender, focando-se em transpor o conhecimento geográfico e as conexões entre os eventos, as instituições e as pessoas que conformam a base de dados em material gráfico de fácil leitura. A ideia é que quando alguém utilizar a plataforma não existam obstáculos ao entendimento do significado da informação apresentada. Ainda bem que é assim, porque caso contrário falar em abertura seria um embuste. A navegação também não é complicada, pelo que a CHCD veio reforçar a ideia de que as interfaces complexas não são sempre necessárias para que seja possível avançar para uma análise complexa. De facto, um excesso de complexidade, especialmente não sendo preciso, impediria a CHCD de fazer o pleno em matéria de inovação aberta. Assim, a plataforma em linha da CHCD - que obedece a uma programação visual minimalista de modo a manter a informação e as ferramentas que incorpora facilmente acessíveis a quem se interessar pela história dos cristianismos na China-constitui um excelente exemplo de como é possível inovar abertamente sem deixar pontas soltas.

\section{2: Inovação social}

É verdade que a inovação social pode ser considerada a partir de vários prismas (Christie e Prasad Chebrolu 2020; Sazesh et al. 2020; Davis 2021). Aqui, contudo, entendemos que uma inovação é social conquanto o empreendimento no seio do qual a inovação se dá apresente um carácter filantrópico. Sendo verdade que a CHCD não tem quaisquer fins lucrativos - não apenas por causa de estar disponível em acesso aberto, 
mas também porque não se envolve em negócios no domínio da publicidade - torna-se possível argumentar a favor do seu carácter filantrópico. De facto, é preciso agir por amor à humanidade - $\varphi \hat{\imath} \lambda o s$, uma das

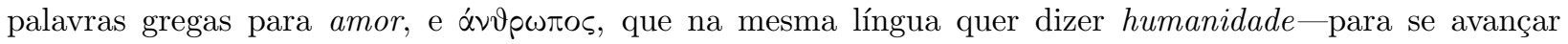
com um empreendimento da envergadura da CHCD - que envolve um largo número de investigadora/es e instituições, e certamente um avultado investimento a nível de dinheiro - e nem sequer equacionar a obtenção de lucros, em sentido pecuniário. Trata-se, a CHCD, de uma inovação no âmbito da economia da investigação que promete ser ainda mais rentável do que muitos outros - a nível de conhecimento - por se tratar de uma inovação social.

\section{3: Inovação tecnológica}

Por muito que a inovação tecnológica represente ä conotação dominante e restrita (the restricted and dominant connotation)ädquirida pela noção de inovação no século XX, trata-se esta apenas de üma das muitas conotações de inovação (one of the many connotations of innovation)"(Godin 2014, 197). Apesar disso, a ubiquidade da inovação tecnológica muito dificilmente pode ser contestada: até o circo - que "dentre a cornucópia de novidades produzidas pela era industrial (among the cornucopia of novelties produced by the industrial era)äpenas, se bem que "quase instantaneamente (almost instantly)", se apropriou da bicicleta - assimilou recentemente üm elevado número de outras inovações tecnológicas que modificaram a sua infraestrutura $(a$ large number of other technological innovations which modified its infrastructure)" (Bouissac 2010, 72-73). No âmbito da economia da investigação, incluindo os sectores da história, a inovação tecnológica passa pelo aproveitamento de potencialidades tecnológicas ainda não exploradas para a produção e valorização do conhecimento, como seja ao longo dos processos de investigação, nos formatos das produções ou na divulgação de resultados. A CHCD representa uma mais valia para a produção de conhecimento sobre a história dos cristianismos na China, acima de tudo porque abre novos horizonte para investigações que pretendam abranger largos períodos temporais, várias áreas geográficas, dados recolhidos em fontes originalmente em diversas línguas e informação referente a instituições, pessoas e eventos relacionados, inter alia, aos vários cristianismos. Tal não é de desprezar, pois embora as estruturas organizacionais protestantes, ortodoxas e católicas sejam realmente diversificadas, a arquitetura flexível da base de dados da CHCD possibilita que tais estruturas sejam documentadas e examinadas conjuntamente, o que constitui tarefa difícil e raramente levada

a cabo nas investigações sobre os cristianismos na China. De acordo com Juma $(2016,5)$, "é discernível que o ritmo da inovação tecnológica é rápido (the pace of technological innovation is discernibly fast), o que gera uma änsiedade intensa que origina esforços no sentido de fazer abrandar a adopção de tecnologia (intense anxiety leading to efforts to slow down the adoption of technology)". Se o que Juma disse é verdade, então podemos dizer que as pessoas e instituições por detrás da criação da CHCD dão mostras de saber lidar muito bem com altos níveis de ansiedade, pois esta não os impediu de avançar com uma iniciativa absolutamente ímpar no âmbito da investigação e da valorização do conhecimento voltadas para a história dos cristianismos na China.

\section{3: Palavras finais}

A história dos cristianismos na China poderia continuar a ser estudada sem a CHCD? Certamente que sim. Continuaria alguém a querer fazê-lo? Seguramente que sim. Então, a CHCD não serve para nada? Aproveitar o lanço e dizer novamente que sim levaria a uma conclusão semelhante à de quem dissesse que, mesmo sem a invenção dos aviões, as pessoas teriam continuado a poder ir de Portugal até à China - de barco ou até a cavalo-, e que por isso os aviões não servem para nada. Ora, quer-nos parecer que a CHCD está para este sector da história - o estudo do passado cristão da China - como os aviões estão para as viagens entre o sul da Europa e a Ásia oriental, permitindo fazer investimentos que serão bastante rentáveis no âmbito da economia da investigação. As métricas na investigação ainda não conseguem ombrear com as grandes bolsas de valores de outros ramos da economia, mas não é por isso que no seio da economia da investigação a competição é menos feroz; e, também no âmbito desta, os sectores que não vierem a inovar irão, ironicamente, passar à história. 


\section{4: Bibliografia de apoio}

Basu, Ron. Managing Projects in Research and Development. Farnham, Surrey, England e Burlington, VT: Gower, 2015.

Blok, Vincent. «Philosophy of Innovation: A Research Agenda». Philosophy of Management 17, n. 1 (1 de Fevereiro de 2018): 1-5. https://doi.org/10.1007/s40926-017-0080-z.

Bouissac, Paul. Semiotics at the Circus. Semiotics, Communication and Cognition 3. Berlin e New York: De Gruyter Mouton, 2010. https://doi.org/10.1515/9783110218312.

Christie, Neha, e Shambu Prasad Chebrolu. «Creating Space for Women Leadership and Participation Through Innovative Strategies: A Case of Tribal Women's Dairy Cooperatives in Gujarat». Em Cooperatives and Social Innovation: Experiences from the Asia Pacific Region, editado por D. Rajasekhar, R. Manjula, e T. Paranjothi, 235-47. Singapore: Springer, 2020. https://doi.org/10.1007/978-981-15-8880-8_16.

Davis, Grace. «Comparative Job Skill Development Initiatives in Northwest Arkansas and Barcelona». Management Undergraduate Honors Theses, 1 de Maio de 2021. https://scholarworks. uark.edu/mgmtuht/ 10.

Godin, Benoit. Innovation contested: the idea of innovation over the centuries. Routledge studies in social and political thought. New York, NY: Routledge, 2014.

Goulet, Frédéric, e Dominique Vinck. «Moving towards Innovation through Withdrawal: The Neglect of Destruction». Em Critical Studies of Innovation, editado por Benoit Godin e Dominique Vinck, 97-114. Cheltenham, UKe Northampton, MA, USA: Edward Elgar Publishing, 2017. https://doi.org/10.4337/ 9781785367229 .

Juma, Calestous. Innovation and Its Enemies: Why People Resist New Technologies. New York: Oxford University Press, 2016. https://doi.org/10.1093/acprof : oso/9780190467036.001.0001.

Peirce, Charles S. Collected Papers of Charles Sanders Peirce. Editado por Charles Hartshorne, Paul Weiss, e Arthur W. Burks. 8 vols. Cambridge, MA: Harvard University Press, 1931.

Sazesh, Alireza, Ruhollah Samiei Samiee, Parviz Saeedi, e Mahmoud Reza Mostaghimi. «Designing a Model of Social Innovation and the Effect on the Behavior and Mental Health of Citizens». Razi Journal of Medical Sciences 27, n. 7 (10 de Outubro de 2020): 120-29. http://rjms.iums.ac.ir/article-1-6363-en.html. 